\title{
The Use of Information and Communication Technologies (ICT) in Front Office Operations of Chain Hotels in Ghana
}

\author{
${ }^{* 1}$ Albert Kwansah Ansah, ${ }^{2}$ Victoria S. Blankson \\ ${ }^{1}$ Department of Computer Science and Engineering, \\ University of Mines and Technology (UMaT), Tarkwa, \\ Ghana
}

\author{
${ }^{1}$ Millicent Kontoh \\ ${ }^{2}$ Department of Consideration of Tourism and Hospitality, \\ Zenith University College, Accra, Ghana
}

\begin{abstract}
The proliferation of Information and Communication Technologies (ICT) coupled with sophisticated network protocols have unveiled new avenues for enterprises and organizations and the hospitality industries cannot be left out. Technology-based systems stand in a pivotal position to offer better service to the populace. Hospitality industries such as hotels can take advantage of the pervasiveness of ICT vis-à-vis technology-based systems to advance some of their operations. This paper seeks to assess the use of Information and Communication Technologies (ICT) in a front office operation of chain hotels in Ghana. The paper determines the extent of the use of information technology in a front office operation of chain hotels in Ghana. The paper continues to assess the effect of the use of information technology in the front office operation of chain hotels in Ghana, thus if the use of ICT has any effect on chain hotels' front office operations. The paper further makes recommendations to chain hotel operators and the Ghana Tourist Authority (GTA) and policy makers on the use of information and communications technology in front office operation in chain hotels. Three chain hotels in Ghana were assessed.
\end{abstract}

Keywords-Front Office Operation; ICT; Chain Hotels; Electronic Point of Sale; Reservation.

\section{INTRODUCTION}

Information technology is everywhere in this day and age and adding to communication technology, the possibility of how it can be used is endless. Information and Communications Technology (ICT) involves the use of computer hardware, software and telecommunication devices to store, manipulate, convert, protect, send and receive data (Olifer and Olifer, 2006). Computer and technological devices have made it easier for professionals to collect, store, manipulate and share data and information both individually and within organizations, small and large, public and private. ICT has become an integral part of human daily activities that sometimes we barely notice its effect, and has had a major impact on the way we live, work and play. The way hotel companies sell to consumers is changing dramatically over the past few years. The use of networking in front office helps very much in sharing information across the hotels in chain. The growth in the use of networked computers is one of the most significant trends in modern computing. Though interconnection of computers in itself is not new, application of networking is seeing a dramatic increase such that it is now one of the major issues in computer and information technology (Ritchie, 2003). Computers are presently widely used in sectors such as banking, education, health, commerce, agriculture, transport, communication. Computers in business operations could be used for typing documents, keeping and retrieving information, data analyses, sending and receiving information over short and long distances. Computers are becoming popular in businesses because work done by them could be very fast, thus results in increasing productivity, accurate in performing repetitive task, store information safely in relatively small space (Olifer and Olifer, 2006).

Despite the increasing popularity of computers, they are still limited to those with the skill to use them. In hotels, computers are used in Accounting for guest, data management, forecasting guest demand for reservations, management of guest services, revenue and reservation management and yield management. These functions could be performed with the aid of management software (Abbott and Lewry, 1999).

The delivery of businesses today is exposed to information and communication technologies either directly or indirectly. Hotels being a subset of the hospitality industry traditionally practise manual system of operation in their front offices as from occupancy of the guest rooms, recording of guest expenditure through to the eventual departure of the guest. Today, these operations are done using the electronic system. The use of information technology in a front office operation of the hospitality industry is fast growing, thus making work easy. Computerization is becoming very important for the efficient and effective operations of the front office.

\section{LITERATURE REVIEW}

\section{A. ICT in Front Office Operations}

Technology is used to push slower moving businesses by providing better service, improved decision making and increasing revenue. Hotel operators are now realising that a brand in itself is not enough (Knowles, 1998). Networks are used to link together computers, storage devices, printers, telephony and other electronic devices (Odom, 2007). The hotel's systems could be networked to share resources via either Local Area Network (LAN) or Wide Area Network (WAN). The LAN helps to share information within a hotel, such as from restaurant to front office and the WAN helps to 
share information from one hotel branch to another within the same chain across different geographical areas. Computers can connect to these networks to use facilities from another hotel or location.

Through ICT, Centralised Reservation Systems (CRS) could be used to exploit data and information resources. The link to a centralised reservation system is considered one of the most important benefits of joining any hotel franchise (Knowles, 1998). Networking the centralised reservation system enhances cost effectiveness, faster communications, and effective exchange of information and efficient management of data (Lucey, 2005).

With a sophisticated central reservation system, a hotel chain provides individual hotels and managers in the chain with a tool to increase reservations, maximize sales, implement yield management, enhance market capabilities and improve quest services. The systems are also linked to airline CRSs to form a Global Reservation System in order to allow travel agents to make direct reservations for their clients. CRS in no doubt faces unprecedented operational and guest services challenges such as system downtime, but may still be essential to survival (Knowles, 1998).

With the numerous positive impact of ICT in businesses, it is hard to imagine a contemporary business functioning without adoption of ICT. ICT permeates every aspect of twenty first century businesses. In hotel front office, computers are used to create bills and invoices, to monitor bookings and reservations, to check-in and check-out guests, to record guest expenditure and share information within and across the hotel. Using IT, guests could stay at the comfort of their homes and private places, communicate with the front office staff via telephony or the Internet to make and confirm reservations. Credit and debit card payments have become an integral part of front office operation today with appropriate software and hardware. Guests can make payment for their booking online to facilitate their reservation, which saves time and reduces queuing at the front offices. Electronic Fund Transfer (EFT) helps quick updates of both hotel and guests' accounts after reservation. Tools such as Computer Managed Learning (CML) and Computer Managed Instruction (CMI) are used as administrative resources to organize guest data, occupancies and vacant rooms.

The way hotel companies sell to customers has changed dramatically over the past few years. In hotel front office operations, the Central Reservation Systems (CRS) is used to share information such as available rooms, room rates etc across hotels within a chain. Global Distribution System (GDS) is also used to link directly the reservation system of hotels, airlines and so on, on a worldwide basis; this can be accessed through seamless connectivity via the internet (Baker et al, 2000).

Technological development certainly would have a great impact on the front office activities. Software packages cover virtually every front office function from reservations, room allocation, and guest history, billing and accounting to the production of management information (Knowles, 1998). It is for this reason that using information and communication technologies in front office operations in chain hotels in Ghana is getting a face-lift with both positive and negative impact. The positive impact may include networking to share information and resources within and across the hotels to enhance check-in of guests and guests' transactions, and easy billing of guests account during check out. With all the good impact of ICT on chain hotel, there should be a budgetary allocation to accommodate the procurement of software, hardware and networking devices and installation, security headaches, training of staff on the use of systems, routine maintenance, redesign of cabling run, on-site systems administrator, disposal of unwanted hardware devices etc. and could bring negative consequence to the hotel owners and managers.

The effect of IT hardware on the staff health cannot be overemphasised. Working with video display terminal (VDT) and the Keyboard can be productive in rewarding and a lot of fun. Unfortunately, prolong postures, coupled with high level of concentration and occasional frustration of things going less than perfect can lead to physical problems like carpal tunnel syndrome (CTS), and computer vision syndrome. Continual clicking and small precise motions involved in mouse use are a repetitive action that could be a health hazard. Improper disposal of unwanted hardware device may also be hazardous to the staff therefore extra money may be spent for apt disposal (Olifer and Olifer, 2006).

The growing importance of computers in the daily lives has raised concerns about possible treat to computers and data. Data collected about clients should be protected from misuse and therefore adequate security measures must be employed, thus data integrity and confidentiality must be ensured. These chain hotels may spend huge amount of money to take care of both hardware and software security measures such as purchasing firewalls and third party backup software to protect data held about their clients or hire backup operators to take charge of data backup backups. Other negative consequence may be losing of huge amount of money during system downtime, that is, when the systems are off-line, clients cannot make reservations both on-line and on the telephone. Chain hotels may also have to spend so much money in training personnel to gain expertise on the use of IT (Olifer and Olifer, 2006). These could affect their budget significantly.

\section{B. Chain Hotel Front Office Operations}

The front office department is the most noticeable department in the hotel. It is traditionally known as reception and it is the focal point of most activities within a hospitality business, whether it is a large or small hotel, a cruise liner, a holiday centre, a time-share resort or a youth hostel. The front office is the first and last place where a guest has direct contact with the business, and is the most visible of all departments within the hospitality industry. The front office is a term accepted as including back of house responsibilities, such as switchboard, accounts, cashier and night audit, front desk, concierge and guest services (Edexcel Limited, 2010). The department may have the front desk, reservations, telephony and the concierge, which provides guests with services and facilities. The main function of the front office department is to support and smooth the progress of guest transaction and services through all the four stages in the guest cycle; that is, pre-arrival, arrival, occupancy and departure. The front office 
department does all the guest transactions such as reservations, check-in and registration, mail and information, uniformed service and baggage handling, telephone calls and messages, guest accounts, check-out and bill settlement (Baker et al, 2000).

Until the 1990's, nearly all hotels were operating under the manual system. With the introduction of computers, hotels are shifting to automated systems. Most five-star hotels operate under the fully automated system. The fully automated systems are computer-based. This is the best system ever used in the hotel industry and it is characterized by the excessive use of departmental software package programs integrated and connected to a main frame or terminal server situated at the front office department.[1, 2]

There are a wide range of point of sale (POS) applications that are compatible with UNIX and Windows. The availability of processing power, data storage, networking, and graphical user interface made it possible to develop flexible and highly functional POS systems. Some of the key requirements that need to be met by modern POS may include high and consistent operating speed, reliability, ease of use, remote supportability and rich functionality. Vendors and retailers are working to standardize development of computerized POS systems and simplify interconnecting POS devices. There is web based POS software that can be run on any computer with an Internet connection and supported browser, without additional software. The POS software is hosted on secure servers with real-time backups.[1,2]

The reservation network system is when guests are referred by another hotel in the same chain or marketing group through affiliate or non-affiliate reservation network systems (Baker et al, 2000). An affiliate reservation system is a reservation system in which all hotels within the same chain participate. Guests can make reservation for accommodation at any hotel within the same group. A non-affiliate reservation network is a subscription, which is designed to connect independently operated hotels; guest can make reservation at any hotel within the same network.

When customers contact the front office with specific details of their proposed reservation, the Central Reservation Officer (CRO) checks room availability and makes reservation directly into the system. (Baker et al 2000.) Making reservation now is easier for guests with the help of computers and Internet because guests do not have to be on site before booking for a room.

Computers are widely used in front office today because of its efficiency and effectiveness in clerical, repetitive, data manipulation, number calculating, speed and accuracy. The involvement of IT does not work only in the front office but links all the departments like housekeeping, food and beverage, conference and health or leisure clubs together. The CRS connects hotels in a chain by sharing information such as available rooms, room rates and so on. Using CRS utilizes yield management to allow better and smoother control of room inventory, provide hotels with a wealth of information that could increase occupancy and revenue (Knowles, 1998). Central Reservation Officers can know the availability of rooms at a particular time of another hotel within the same chain (Baker et al, 2000).

Customers could check on marketing information, room availability and room rates with the use of the internet. The reservation clerk constantly updates information on the internet to reflect the current activities of the hotels. Through IT, automatic check-in is available to guests at the front office. Guests need credit cards to be issued with a computer-coded room key (Abbott and Lewry, 1999). The credit cards are needed to activate these machines to issue the computer-coded room key. The machine displays a menu showing the available rooms and their rate for guests to make their reservations and booking.[3]

\section{METHODOLOGY}

Data were collected from three chain hotels in Ghana; namely Golden Tulip, Novotel and Holiday Inn. Questionnaire (Appendix I), which included both open-end and close-end questions were developed and sent to the front office personnel in the above mentioned chain hotels. Respondents were expected to tick the appropriate check box. Unstructured interviews were also conducted with front office personnel. Some officials from the Ghana Tourist Authority (GTA) were not left out in the interview and were also made to participate in the questionnaire. A quantitative approach of data analysis was used on the data collected by means of questionnaire and interviews. Tables and charts were used to collate the data for the analysis.

Test questions such as; "Has the use of information technology made any effects on chain hotels in Ghana?" and "what significant change has information technology brought on the front office operations of chain hotels in Ghana?" were used in the research. The research was limited to only chain hotels in Ghana so as to realize the full impact.

\section{DATA ANALYSIS AND DiscuSSION OF FINDINGS}

Demographic data of the respondents are analyzed here. Forty Eight questionnaires were given to Forty Eight staffs in three selected chain hotels and Ghana Tourist Authority, which was collected after a fortnight. Forty questionnaires were responded to out of the forty eight. Out of the 40 respondents, 28 were females representing $70 \%$ and 12 were males, which represent $30 \%$. Table 1 and Figure 1 both show the number of questionnaires given to each hotel and the percentage of responded and unresponded questionnaires and Table 2 shows the age distribution of the respondents.

View on whether the use of ICT has brought any impact positively or negatively on the staffs and hotel as a whole as far as the front office operations are concerned is as shown on Table 5. 
TABLE I. QUESTIONNAIRE RESPONDENT TABLE

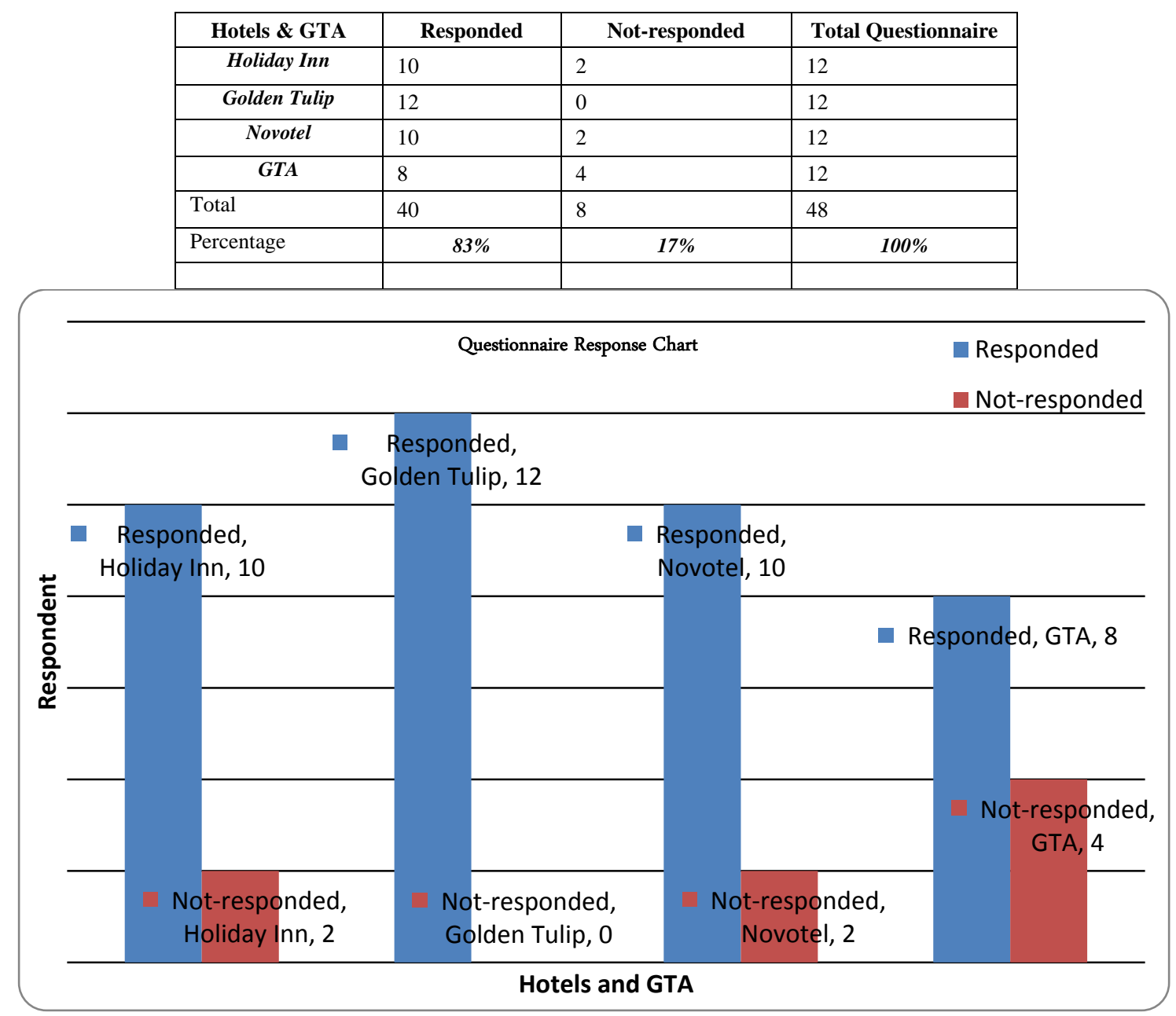

Figure 1. Questionnaire Respondent Chart

TABLE II. AGE DISTRIBUTION OF RESPONDENTS

\begin{tabular}{|c|l|l|}
\hline Age (yrs) & \multicolumn{1}{|c|}{ Number of Respondents } & \multicolumn{2}{|c|}{ Percentage (\%) } \\
\hline $\mathbf{2 2}-\mathbf{2 5}$ & 12 & 30 \\
\hline $\mathbf{2 6}-\mathbf{3 0}$ & 18 & 45 \\
\hline $\mathbf{3 1}-\mathbf{3 5}$ & 6 & 15 \\
\hline $\mathbf{3 6}-\mathbf{4 0}$ & 4 & 10 \\
\hline Total & $\mathbf{4 0}$ & \multicolumn{2}{|c|}{$\mathbf{1 0 0}$} \\
\hline
\end{tabular}

TABLE III. INTERVIEW ON IMPACT OF IT ON FRONT OFFICE OPERATIONS

\begin{tabular}{|c|c|c|c|}
\hline Hotels \& GTA & Positive & Negative & Total Interviews \\
\hline Holiday Inn & 4 & 1 & 5 \\
\hline Golden Tulip & 4 & 2 & 6 \\
\hline Novotel & 4 & 0 & 4 \\
\hline GTA & 3 & 0 & 3 \\
\hline Total & 15 & 3 & 18 \\
\hline Percentage & $83.3 \%$ & $1.7 \%$ & $100 \%$ \\
\hline
\end{tabular}

TABLE IV. EDUCATIONAL LEVEL OF RESPONDENTS

\begin{tabular}{|c|l|l|}
\hline Educational Level & \multicolumn{1}{|c|}{ Number of Respondents } & Percentage (\%) \\
\hline Master & 4 & 10 \\
\hline Degree & 8 & 20 \\
\hline HND & 8 & 20 \\
\hline Advance Diploma & 12 & 30 \\
\hline Diploma & 8 & 20 \\
\hline
\end{tabular}




\begin{tabular}{|l|l|c|}
\hline Total & 40 & 100 \\
\hline
\end{tabular}

TABLE V. IMPACT OF IT ON FRONT OFFICE OPERATIONS

\begin{tabular}{|c|l|c|}
\hline Impact & Number of Respondents & Percentage (\%) \\
\hline Positive & 35 & 87.5 \\
\hline Negative & 5 & 12.5 \\
\hline
\end{tabular}

\section{CONCLUSION}

The paper looked in totality whether the impact of using Information and Communication Technologies (ICT) in the front office operations of chain hotels is positive or negative. 87.5 per cent of the 40 respondents responded positive to the impact of using ICT in the front office of chain hotels and 12.5 per cent responded negative to the same. From Table 3, it could be seen that the respondents were carefully chosen and could say that the result in Table 4 is authentic. The use of IT has reduced queues to barely negligible at the front office during check-in and check-out because of the use of the Internet and Electronic Point-of-sale (EPOS) system that transfers instant charges on guest accounts. Guest can remotely inspect their account from the convenience of their abode.

\section{RECOMMENDATION}

After careful consideration, the following recommendations could be drawn;

- The front office staff should have adequate IT training in the use of the ICT equipment.

- The front office staff must receive training to help them prevent Video Display Terminal (VDT) and Carpal Tunnel Syndrome (CTS) threats.

- Chain hotels should occasionally organize refresher courses for the front office staff to introduce them to new software and hardware applicable to their operations.

- GTA should sensitize chain hotels in Ghana on the importance of networking the operations of the hotel using ICT.

- The GTA should organize seminars and workshops at least annually on the use and importance of ICT not only the chain hotels but the hospitality industries as a whole.

- Chain hotels should encourage and promote the use of ICT in their front office operations.

- Policy makers in the tourism industry should make sure that all chain hotels in Ghana use ICT to network all their branches across the country.

- Chain hotels should encourage their guests to use the internet and telephony to make reservations.

\section{REFERENCES}

[1] Olifer, N. and Olifer, V. (2006) Computer Networks, Principles, Technologies and Protocol for Network Design, John Wiley and Sons Ltd, England.

[2] Ritchie, C. (2003) Operating Systems: Incorporating UNIX and Windows, Continuum, London and New York. 4th Edition

[3] Abbott, P. and Lewry, S. (1999) Front Office: Procedures, Social skills, Yield and Management, Elsevier, United Kingdom.

[4] Knowles, T. (1998) Hospitality Management: An Introduction, Prentice Hall, London. 2nd Edition

[5] Odom, W. (2007) CCENT/CCNA ICND1: Official Exam Certification Guide, Cisco Press, Indianapolis. 2nd Edition

[6] Lucey, T. (2005) Management Information Systems, Book Power, Britain.

[7] Baker, S., Huyton, J. and Bradley, P. (2006) Principles of Hotel Front Office Operations, Thomson Learning, London.

[8] Edexcel Limited (2010) Front Office Operations in Hospitality, BTEC Level 3 Nationals specification in Hospitality, Issue 1

[9] 1Jamel, C. (2010) Front Office Operations, Retrieved from www.satm.bilkent.edu.tr/ jamel/Foo/52148-Chapter\%205.doc (23 June 2010 12:25pm)

[10] 2 Kofax Front Office Server, Retrieved from http://www.kofax.com/downloads/datasheets/ds-kofax-front-officeserver-en.pdf (23 June 2010 12:32pm)

[11] 3Wikipedia (2010) Hospitality Point of Sale Systems, Retrieved from http://en.wikipedia.org/wiki/Hospitality_point_of_sale_systems\#Hospita lity_industry (24/06/10 11:29 am)

\section{AUTHORS PROFILE}

Albert Kwansah Ansah obtained his MSc in Mobile Computing and Communications from the University of Greenwich in London, United Kingdom in 2008. He is currently a Computer Science and Engineering lecturer at the University of Mines and Technology, Tarkwa-Ghana and a member of International Association of Engineers (IAENG). His research interests include Wireless, Satellite and Mobile Communication \& Application, Network Coding and Antenna Design.

Victoria S. Blankson is currently a final year BBA Hospitality Management Student in the Department of Consideration of Tourism and Hospitality, Zenith University College, Accra-Ghana. Her research interests are Front Office Operations and Hotel Management.

Millicent S. Kontoh was born in Nkawkaw, Ghana in 1982. She graduated from Tver State Technical University with Masters in Computers, Complex Systems and Networks in 2007. She is currently a lecturer at the Computer Science and Engineering Department, University of Mines and Technology, Tarkwa Ghana. M. S. Kontoh has worked in several institutions including Registrar General's Department under the Ministry of Justice and Attorney General, Ghana, Zenith and Pentecost University Colleges in Ghana. She is an associate member of the Institute of Electrical and Electronic Engineers, IEEE and served as its Student Branch Counsellor at Pentecost University, and currently an executive member of IEEE Ghana Section. Her research interests include Modelling of Software and Database Systems, Systems Analysis and Design. 


\section{APPENDIX I}

The use of Information and Communication Technologies (ICT) in front office operations in chain hotels

\section{QUESTIONNAIRE}

Please tick $(\sqrt{ })$ or provide the appropriate answers to the following questions where applicable.

1. Grade of the Hotel.

2. Age between: 22-25 yrs [ ] 25-30 yrs [ ] 30-40 [ ]

3. Gender: Male [ ] Female [ ]

4. Educational Level: Diploma [ ] Higher National Diploma (HND) [ ] Degree [ ] Masters [ ]

5. Marital status: Single [ ] Married [ ] Divorced [ ] widowed [ ]

6. How long have you been working in this hotel?

7. What is your current position?

8. How

long have

you
been in this position?

9. How long has

your hotel

or office

been

using

Information

Technology?

10. Has the use of Information and Communication Technologies made any effect on your hotels and office? Yes [ ] No [ ] answer

$$
\text { on }
$$

$$
\text { either }
$$$$
\text { positive }
$$

11. What significant change has Information Technology brought on the front office operations or your office? Positive [ ] Negative [ ]

Please give reasons for $\quad$ your answer.

12. How many times does your hotel go on training?

Once a year [ ] Twice a year [ ] Thrice a year [ ]

13. What impact does the training bring on you (front office staff) and the hotel?

Positive [ ] Negative [ ]

14. How is the use of Information Technology in front office operation? use $[\quad]$

Easy to use [ ] Difficult to Please give reasons for your answer. 